\title{
EL MARISTÁN Y AL-MADRASA; HOSPITAL-ESCUELA DE MEDICINA (I)
}

\author{
SAID-FARAH M ${ }^{1}$
}

El Renacimiento supuso un florecimiento científico, cultural y político, que dejó muy lejos la oscura época medieval. Hasta entonces, Occidente no disponía de las fuentes del pensamiento del Mundo Antiguo, necesarias e indispensables para desarrollar un conocimiento propio. Entre éstas se encontraban las enseñanzas médicas basadas en textos de Aristóteles, Hipócrates y Galeno de Pergamo. Muchos escritos han permitido la aparición de textos y enciclopedias que han sido referencia durante centenares de años.

El profeta Mahoma había aconsejado a sus seguidores, "Buscad el conocimiento, aun sea en China»; pues, "Quien deja su hogar en busca de conocimiento, camina en el sendero de Dios». En obediencia a este mandato, los musulmanes enviaron comitivas por toda Siria, Bizancio, Armenia y otras partes en búsqueda de manuscritos. De especial interés fueron los clásicos griegos como Antíoco de Atenas, Apolonio, Aristóteles, Arquímedes, Dioscórides, Doroteo de Sidón, Euclides, Galeno, Herón, Hipócrates, Platón, Polemón, Tolomeo, Sócrates y Tales, entre otros; todos desconocidos y/o prohibidos por la Iglesia Católica; aunque estudiosos europeos acudían a estos centros para realizar traducciones personales al latín, atribuyéndose algunos de ellos su autoría.

La obtención de los conocimientos pasaba por dos fases; en primer lugar se enviaban misiones de sabios musulmanes, cristianos y judíos con el objetivo de adquirir manuscritos y promocionar así el conocimiento, prohibiendo cualquier tipo de destrucción y promoviendo la disciplina y la tolerancia. Posteriormente, los científicos añadían nuevas observaciones y experiencias contribuyendo así a un avance en la práctica de la ciencia.

El árabe se convirtió de esta forma, en la lengua internacional del saber y la diplomacia, gracias a la traducción y la transmisión de los conocimientos. Las capitales musulmanas más importantes del momento fueron Damasco, El Cairo y Bagdad, las cuales además albergaban un ávido entusiasmo por traducir las escrituras griegas esenciales al árabe (1-10).

Una sentencia del profeta Mahoma reza: «Sólo hay dos ciencias, la teología para la salud del alma y la medicina para la salud del cuerpo».

La primera delegación que se envió, una de las más destacadas enviadas al reino de Bizancio, fue la del médico Ibn al-Nadim, con su famoso catálogo de libros de la época griega, siríaca y bizantina y más de 57 traducciones asociados a la Casa de la Sabiduría. Otros nombres destacados son el del sabio cristiano de Al Hira director de «La casa de sabiduría», Hunain Ibn Isaac (808-872 d.C) médico y traductor que escribió «Tratado del ojo» y el «Libro de las drogas simples», e Ibn Qurra (836901 d.C) director de grandes hospitales y médico de la Corte de tres califas, escribió su obra médica conocida «El tesoro» $(1,2,7,8,11)$.

El conocimiento y las enseñanzas de sus científicos supusieron en la práctica que las instituciones antecesoras de los hospitales modernos; el nosocómeion bizantino, el maristán islámico y el hospital europeo; difirieran entre sí, tanto en lo relacionado

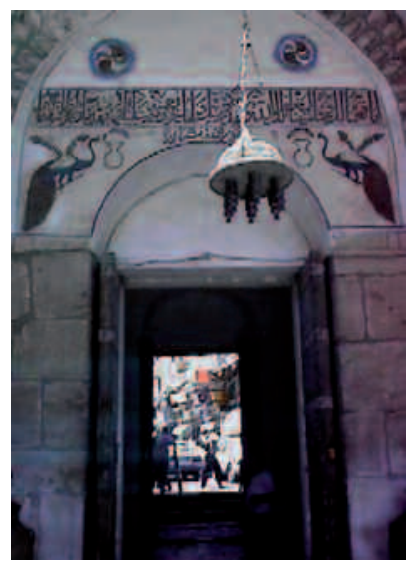

El Maristán de Nuruddin en Damasco-Siria.

\footnotetext{
1 Doctor en Medicina. Madrid.

E-mail: m.said@teleline.es
} 


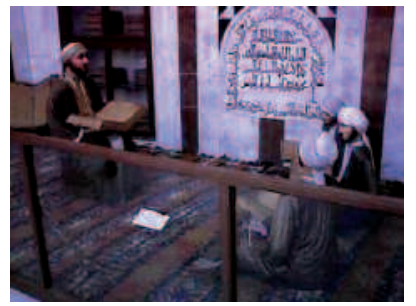

Al-Madrasa - Escuela de medicina.

con la atención a los pacientes, como a sus funciones, metodología y continuidad del saber adquirido.

El primer hospital que combinó la enseñanza de la medicina con la atención de enfermos fue el establecido en la ciudad persa de Jundi-Shapur, que significaba «jardín hermoso». Conquistada por los musulmanes en el año 636 d.C; su gran hospital y escuela, permanecieron intactos, y sirvieron de patrón para las escuelas médicas islámicas. Los hospitales recibieron el nombre persa de «maristán».

Las principales capitales musulmanas construirían sus propios hospitales en años posteriores; El primer y mayor maristán de fama en la época, fue fundado en Damasco en el 707 d.C. bajo el mandato del califa Al Walid Mansur; cien años después contaba con veinticuatro médicos. A su vez, Bagdad disponía del primer maristán, hacia 800 d.C. fundado por el califa Al-Rashid, como modelo de hospital universal y académico.

La enseñanza médica se daba principalmente en los hospitales; ya en el año 931 d.C. había 860 médicos titulados en Bagdad. En El Cairo, el primer hospital fue fundado por Ibn Tulún hacia el año 872 d.C. y contaba con su propia biblioteca, que tenía más de 100.000 libros (1-5).

Años más tarde se crearon otros hospitales que adquirirían gran renombre como el Adudi en Bagdad, fundado en 981 d.C., con residentes y más de



Madrassa y Maristán de Qalawen en El Cairo.
24 consultores. En Damasco, el sultán de Siria y Egipto Nuruddín Zenguí (1118-1174 d.C.) edificó uno de los hospitales más grandes de la época.

El sultán mameluco Qalawun fundó en 1284 d.C. el hospital al-Mansouri en El Cairo; este maristán podía albergar hasta ocho mil pacientes de ambos sexos separados, con departamentos para cada especialidad, y comunicado con el madrasa de Qalawun; Había mezquita para los pacientes musulmanes, al igual que una capilla para los pacientes cristianos $(3-5,12)$.

Los hospitales eran muy espaciosos dejando circular así libremente el aire y el agua de sus fuentes y estanques. "Habiéndose encargado a al-Razí que escogiese el barrio más sano de Bagdad para construir un hospital, empleó el siguiente medio, que no rechazarían hoy los partidarios de las teorías sobre los microbios. Suspendió unos pedazos de carne en varios barrios de la ciudad, y declaró más sano aquél donde la carne tardó más en descomponerse» (6).

Estaban equipados para el tratamiento de todas las patologías y casos particulares como desórdenes mentales. Poseían quirófano, dispensario, farmacia, biblioteca y cuartos de conferencias donde impartían sus enseñanzas, los diferentes maestros sabios en el madrasa o escuela del maristán, como el eminente médico Al Daucar, entre cuyos alumnos estuvo Ibn Nafis (4). Los musulmanes establecieron la primera escuela medieval de farmacia convirtiéndola en profesión separada de la Medicina y de la Alquimia, e introdujeron nuevos preparados farmacéuticos: jarabe (del árabe sharáb), julepes (shulab), agua de rosas, etc. Implantaron útiles técnicas de destilación, cristalización y calcinación así como el baño de vapor en el tratamiento de la fiebre $(1-5,11)$.

El hospital y la escuela médica en Damasco fue un modelo de los maristanes de la época, tenían cuartos elegantes y una biblioteca extensa. Dicen que la gente sana fingía de enfermedad para gozar de su cocina. En Damasco, había un hospital separado para los leprosos, mientras en la Europa medieval incluso seis siglos más adelante, los leprosos fueron condenados a muerte con la quema por decreto real (2).

En los maristanes o nosocomios para los enfermos mentales, se empleaba técnicas novedosas como la musicoterapia, apelando al murmullo del agua de las fuentes o a suaves melodías ejecutadas con el laúd, el qanún o la flauta de caña, y la terapia ocupacional para curar a los perturbados mentales (4). Algo bastante distinto, incluso hoy en día, a las puertas del siglo XXI, donde todavía se apela a 
métodos psiquiátricos como el electroshock, chalecos de fuerza, el uso de fármacos nocivos en las «curas de sueño», la lobotomía, etc., o a interminables y costosas secciones de psicoterapia con bastantes magros resultados.

Fernando Díaz-Plaja describe el trato de los dementes de la época que; "Al igual que en el resto del mundo islámico, los locos, de no ser peligrosos, quedaban en libertad y no eran importunados nun$c a »$ (13). Actualmente, el maristán que está cerca de Jan el Jalili, en El Cairo, sigue proporcionando asistencia médica a sus huéspedes empleando la música y el ruido del agua para curar a los dementes (5).

En el siglo octavo, los árabes construyeron maristanes o hospitales mentales en Fez (Marruecos), en Bagdad en 705 d.C, en El Cairo 800 d.C, y en Damasco y Aleppo en 1270 d.C. Los primeros hospitales de la salud mental en Europa fueron construidos en la España musulmana del siglo XIV; el primero fue en Granada en 1365 d.C, fecha que se conoce por la inscripción que existía en la fachada del edificio donde hoy se encuentra el Museo de la Alhambra. El maristán alcanzó una posición destacada por brindar asistencia médica en una gran construcción majestuosa, con una gran plaza, abundante agua, lugares de abluciones y aire sano (3-5).

Por otra parte, muchos redescubrimientos de la actualidad fueron reconocidos por vez primera a médicos islámicos de la época de aquellos maristanes; Como ejemplo notable, cabe destacar Ibn Nafis (1210-1288 d.C), nacido en Damasco y médico personal del sultán Al Zahir Baibers, fue autor de la primera descripción conocida de la circulación sanguínea pulmonar más por deducción que por disección, en su «Shaar Tasrih Al Qanun» o «Comentario sobre la Anatomía del Canon de Avicena». Trescientos años después, se le atribuía al médico inglés William Harvey (1578-1657) el descubrimiento por observación anatómica directa, también el primero en describir el concepto de la circulación coronaria $(4,5,14,15)$.

Luisa F. Aguirre de Cárcer, relata aspectos de la vida social y ordenación jurídica del Andalus medieval, a través de una recopilación de fetuas del cadí (juez en árabe), cordobés Ibn Sahl y de una médico o tabiba, género femenino de tabib, médico en árabe y sus honorarios; la cual trató enfermedades infantiles. De este dato se deduce que las mujeres en aquella época medieval encontraban un hueco en el campo sanitario lo suficientemente importante para llegar a la categoría de tabiba o médica (16).
Los títulos sociales de los médicos eran de orden descendente: hakim (sabio), tabib o tabiba (médico o médica), mutabbib (médico practico incluye técnicos en sangría y de conocimiento limitado en drogas y fórmulas) y mudawi (mero empírico) (3).

Los informes clínicos y expedientes de los pacientes fueron escritos y preservados para la enseñanza y los registros fueron mantenidos por vez primera en la Historia. Esto se debe a que los hospitales, tenían su propio dispensario, sala de conferencias y bibliotecas que contenían los libros más actualizados, como la biblioteca del hospital de Tulun, fundada en El Cairo hace 1135 años (4,5).

En Bagdad en 931d.C, el califa al-Muqtadir, a consecuencia de la muerte ocasionada a un hombre por el error de un médico, ordenó a su médico jefe, Sinan Ibn Thabit Ibn Qurrah, que fuera examinado todo aquel que practicara el arte de curación y les firmase licencia personal. Durante el primer año del decreto, más de 860 licenciados fueron examinados solamente en Bagdad, por un oficial del gobierno, llamado Muhtasib. Éste también era inspector de pesas y medidas de los comerciantes y boticas que dispensaban medicamentos y hierbas medicinales, lo que se conoce actualmente como Agencia del Alimento y de la Droga (FDA).

Tanto en Granada como en la España Cristiana se implantan los exámenes para poder ejercer este arte. Esto era conocido en el siglo XIII, a través del cuento de Las Mil y una noche. La doncella Teodor, uno de cuyos episodios está centrado en un examen de medicina $(17,18)$.

Este modelo de maristán-madrasa, no sólo salvo el saber clásico; también ha contribuido al desarrollo académico y cultural en la enseñanza médica por maestros que supieron transmitir las ideas del pensamiento médico antiguo, y desarrollar métodos y técnicas de medicinar. Las traducciones de los textos árabes al latín en las escuelas de traducción como la de Toledo, donde trabajaba Gerardo de Carmona, en siglo XII, que tradujo más textos que nadie del árabe al latín. Como cuenta Juan Vernet, estos textos vertidos al latín, circularon de corte en corte, de monasterio en monasterio; y así, a toda Europa.

\section{BIBLIOGRAFIA}

1. De Micheli-Serra A. Notas sobre la medicina del Antiguo Islam. Gac Med Mex 2002; 138: 281-285. 
2. Nagamia HF. Islamic Medicine History and Current Practice. JISHIM 2003; 2: 19-30.

3. De Micheli A. En torno a la evolución de los hospitales. Gac Med. Mex 2005; 141: 57-62.

4. Syed IB. Islamic Medicine: 1000 years ahead of its times. JISHIM 2002; 2: 2-9.

5. Medicina. Disponible en: http://www.organizacionislam.org.ar/civilizacion/medicina.htm

6. Lebon G. La civilización de los árabes. Buenos Aires: El Nilo; 1974: 441-442.

7. Cristóbal Bescós JA. La Oftalmología Medieval. El legado de los árabes. Microcirugía Ocular 2005; N. ${ }^{\circ} 4$ : 155 207.

8. Murube J, Díab F, Muñoz-Negrete F, Sales-Sanz M. La primera imagen científica del ojo. Studium Ophthalmologicum 2007; 25: 65-73.

9. Steiger A. Tradición y fuentes islámicas en la obra de Alfonso X el Sabio. Revista del Instituto Egipcio de Estudios Islámicos 1985-1986; 23: 23.

10. El-Madkouri Maataoui M. Escuelas y técnicas de traducción en la Edad Media. Disponible en: http://www.um.es/tonosdigital/znum11/portada/tritonos/tr itonos-edadmedia.htm

11. Majeed A. How Islam changed medicine. BMJ 2005; 331 : 1486-1487.

12. Jalili M. The public health of Rhazes. Hist Sci Med 1982; 17: 105-110.

13. Díaz-Plaja F. La vida cotidiana en la España musulmana. Madrid: Edaf Ed.; 1993.

14. Al-Ghazal SK. The discovery of the pulmonary circulation - Who should get the credit: Ibn Al-Nafis or William Harvey. JISHIM 2002; 2: 46-48.

15. Soubani AO, Khan FA. The discovery of the pulmonary circulation revisited. Ann Saudi Med 1995; 15: 185-186.

16. Aguirre de Cárcer LF. Sobre el ejercicio de la medicina en al-Andalus: una fetua de Ibn sahl. Anaquel de Estudios Árabes 1991; 2: 147-162.

17. Vernet J. El Reino de Granada: Islam y al-Andalus. Disponible en: http://www.islamyal-andalus.org/control/ imprimir.php? $i d=494$

18. Vernet J. La cultura hispanoárabe en Oriente y Occidente. Barcelona: Seix y Barral Hnos; 1978. 